\title{
El campo patrimonial y museístico: un espacio cultural conflictivo ${ }^{1}$
}

\author{
The heritage and museums field: \\ A controversial cultural space
}

\author{
Iñaki Arrieta Urtizberea \\ Departamento de Filosofía de los Valores y Antropología Social \\ Universidad del País Vasco / Euskal Herriko Unibertsitatea. \\ Donostia - San Sebastián
}

\section{RESUMEN}

Los procesos de patrimonialización y musealización de la cultura no responden a criterios históricos o estéticos, sino identitarios. No atañen a científicos, especialistas y políticos solamente, sino a colectivos sociales. La elección de unos bienes culturales no es una consecuencia objetiva de sus características formales, es el resultado de la selección llevada a cabo por agentes sociales con el fin de representar una identidad grupal. Pero ningún colectivo social es uniforme, sino, al contrario, es diverso y complejo, de tal modo que los referentes identitarios y, consecuentemente, los bienes culturales no tienen por qué ser unívocos. Más allá de los discursos asépticos, muchos de esos procesos se presentan conflictivos. Diferencias acerca de los referentes identitarios y de los usos que se les quieren dar a los bienes culturales acarrean que el campo patrimonial y museístico sea un espacio de confrontación de intereses y valores. Este artículo presenta y analiza los conflictos que surgieron en el municipio vasco de Legazpi cuando se inició el proceso de patrimonialización y musealización de la producción del hierro.

Palabras clave: Patrimonio cultural, Museos, Campo social, Identidad y turismo.

\section{SUMMARY}

The processes of acceptance as heritage and musealisation do not respond to history or aesthetics-related criteria, but rather to identity-related criteria. They do not concern scientists, specialists and policy-makers alone, but also social groups. The choice of cultural assets is not an objective consequence of their formal characteristics. It is the

${ }^{1}$ Proyecto de investigación (CSO2008-05065) financiado por el Ministerio de Ciencia e Innovación. Agradezco a Oriol Beltrán, a los evaluadores externos de la RDTP y a los miembros de su Consejo de Redacción las sugerencias planteadas y las correcciones propuestas. 
result of the selection made by social agents so as to represent a group identity. But no social group is homogeneous; on the contrary they are diverse and complex so the identity references, and therefore the cultural assets, do not have to be univocal. Beyond the aseptic discourses, many of these processes are controversial. Differences regarding the identity references and the uses to be made of cultural assets lead to the field of heritage and museums being spaces where interests and values clash. This article presents and analyses the conflicts that arose in the Basque municipality of Legazpi when the process of musealisation and acceptance of iron production as heritage first started.

Key words: Cultural Heritage, Museums, Social Field, Identity and Tourism.

\section{INTRODUCCIÓN}

A mediados del siglo xx los criterios históricos, estéticos y monumentales que legitimaban los discursos y las acciones patrimoniales y museísticos comenzaron a ponerse en cuestión (Agudo Torrico y Fernández de Paz 1999: 10; González-Varas 2003: 43). Objetivados y naturalizados por especialistas en historia y bellas artes, aquellos criterios no hacían sino enmascarar el porqué implícito de la conservación del patrimonio o de la construcción de museos. El motivo no era científico ni estético, sino identitario.

Con la Revolución Francesa y la emergencia de la estructura político-administrativa y territorial del Estado-nación, la consolidación de una identidad común en todo el territorio nacional pasó a ser una cuestión de Estado (Bauman 2001: 30). Para ello el Estado recurrió a los museos y al patrimonio histórico-artístico (Cuche 2002: 113; Díaz Balerdi 2008: 101; Macdonald 2003: 1) y asumió las competencias en materias de su conservación y fomento. A través del patrimonio, el Estado-nación buscaba manipular social y políticamente a todos los colectivos sociales de su territorio, fomentando o consolidando una opción identitaria respecto a otras (García García 1998: 13). Sin embargo, desnaturalizados y "desobjetivados" los criterios históricos y artísticos en los años 60, el patrimonio comenzó a definirse, política y teóricamente (Agudo Torrico 1999: 39; Moreno 1999: 326; Prats, 1997: 22; UNESCO 2002: 13-14), en función de lo identitario, lo que condujo también a cuestionar las competencias exclusivas del Estado a la hora de declarar, activar o poner en valor los bienes culturales. De ahí en adelante, cualquier colectivo que quisiera simbolizar su identidad podría valerse del patrimonio. No tendría que contar necesariamente con la aquiescencia de funcionarios y técnicos del Estado y de especialistas en ciencias humanas. En definitiva, el patrimonio pasó a ser una cuestión social — concierne a un grupo humanoy cultural —un medio para representar y consolidar una identidad colectiva-, y a adjetivarse como "cultural" en vez de "histórico-artístico".

Así, no es de extrañar que el progresivo interés por las cuestiones identitarias, como consecuencia de los procesos de individualización, plu- 
ralismo, incertidumbre y heterogeneidad, que surgieron con la primera modernización y que se han acentuado con la globalización o mundialización (García Canclini 2004: 162), haya traído la diversificación de los procesos de patrimonialización (Ariño Villarroya 2002: 19), más allá de los promovidos por los Estados-nación. De este modo, surgen, entre otros, los ecomuseos, museos comunitarios o museos de barrio (Agudo Torrico y Fernández de Paz 1999: 14; Binette 2009: 132; Camarena Ocampo y Morales Lersch 2009: 118; Dubuc 2008: 65; Duclos y Veillard 1992: 129; Mairesse 2007: 189; Roigé Ventura, 2007: 24), como proyectos patrimoniales que representan y presentan identidades colectivas al margen de las nacionales. Incluso, en los últimos años, la emergencia de nuevas propuestas identitarias, promovidas por organizaciones, asociaciones y movimientos transnacionales, está cuestionando o reorientando la función de los museos estatales, legitimadores de la identidad nacional (Rogan 2003: 55).

Si el patrimonio cultural se constituye a partir de la identidad colectiva, deja de ser una cuestión que atañe solamente a técnicos, especialistas y políticos para pasar a ser un asunto de toda una colectividad (Chevalier 2000: XI). No obstante, en la medida en que todo colectivo es plural y complejo - "que contiene diversas series de asociaciones y grupos basados en distinciones de clase, género, orientación sexual, religión, creencias morales e ideología política” (Kymlicka 1996: 35)—, el patrimonio cultural se ve atravesado por diferentes propuestas identitarias y diversos sentimientos de pertenencia. La identidad o las identidades de los individuos no son absolutas, sino relacionales (Cuche 2002: 118), no son estáticas, sino dinámicas (Caro Baroja 1985: 11), aunque mantengan cierto grado de estabilidad en el tiempo. Así, si la diversidad intergrupal y, consecuentemente, identitaria ha dado lugar a múltiples y heterogéneas iniciativas patrimoniales y museísticas, la pluralidad intragrupal puede dar pie a desencuentros y conflictos entre los miembros del colectivo social a la hora de conservar o fomentar ciertos bienes culturales. Investigar el patrimonio cultural nos obliga, entonces, a abordar su "complejidad casuística" (Prats 2005: 19), a preguntarnos, tal como lo hace Cátedra, acerca de "¿quién define la cultura y el patrimonio cultural, quién sistematiza y elabora la cultura?" (1998: 89) o "¿quién hace patrimonio?", como lo formulan Hernández Ramírez y Ruiz Ballesteros (2008: 129). Unas preguntas raramente contestadas, como muy bien afirman dichos autores. La literatura especializada está dominada por estudios e investigaciones dedicados a las características formales de los bienes culturales o a las "estructuras anónimas"² (García Canclini 2004: 156) que activan o ponen en valor el patrimonio. Pocas veces se abordan esas preguntas.

\footnotetext{
${ }^{2}$ Obviamente no es posible descender a este nivel de complejidad casuística en todas las investigaciones que se llevan a cabo acerca del patrimonio cultural y los mu-
} 
La categoría de "campo", "campo patrimonial", definida como el juego de relaciones de fuerza dirigidas por los agentes implicados y que tienen como objetivo hacerse con el monopolio de la definición y de los usos legítimos del patrimonio cultural (Bourdieu 2000: 118), adquiere aquí su pertinencia. Valiéndonos de ella podemos dar cuenta de la complejidad casuística de cualquier proceso de patrimonialización. Nuestro objeto de estudio son los agentes participantes, sus intereses y relaciones. Las características formales, históricas y estéticas de los bienes culturales quedan en un segundo plano.

La existencia de un campo implica que todos los agentes involucrados acepten su doxa, es decir, lo que configura las reglas del campo (Bourdieu 2000: 114); en nuestro caso, que el patrimonio cultural y el conjunto de bienes culturales que lo constituyen simbolizan la identidad colectiva. Así, todo conflicto en el campo presupone un acuerdo mínimo entre los agentes, aunque sean antagonistas, a saber, la aceptación, consciente o inconscientemente, de la doxa. En el juego de relaciones o en la lucha por hacerse con el control del campo patrimonial, los referentes identitarios pueden cambiar, pero, en todo caso, su configuración permanece idéntica, es decir, la vinculación del patrimonio y los bienes culturales con la identidad. Hoy en día, esta doxa patrimonial se ha endoculturizado y no se prevé un cambio en el campo, semejante al acaecido en los años 60, tal como lo hemos descrito al comienzo.

Para que un campo patrimonial concreto se constituya hacen falta unos objetos y unos agentes interesados en convertirlos en bienes culturales. En el caso que vamos a abordar en este artículo, los objetos son los relacionados con la producción del hierro en el municipio de Legazpi (Gipuzkoa, País Vasco) y los intereses, los de los agentes locales y superlocales implicados en su patrimonialización. La posición de los diferentes agentes dentro del campo - la que determina que unos intereses prevalezcan sobre otros- depende del volumen de capitales que posean y de su composición. Contamos con cuatro tipos de capitales ${ }^{3}$ : el económico (recursos económicos), el cultural (conocimiento e información acerca del campo patrimonial), el social (red de relaciones) y el simbólico (poder reconocido en ese campo para imponer, a su vez, dicho reconocimiento).

seos. Nos referimos, por ejemplo, a aquellos trabajos que realizan un estudio diacrónico o sincrónico de muchos y variados proyectos patrimoniales y museísticos. No obstante, un avance importante se daría si el objeto de investigación no fueran las características formales de los bienes culturales, sino los agentes que los activan o los ponen en valor.

${ }^{3}$ Presentamos brevemente los definidos por Pierre Bourdieu (Álvarez Sousa 1996: 147). 
Considerar el patrimonio cultural como un campo nos acerca a otras aproximaciones analíticas que se hacen al mismo. Categorías como "activación" (Prats 2005: 19), "construcción social" (Prats y Santana 2005: 10), "mercantilización" (Pereiro Pérez y Sierra Rodríguez 2005: 10), "puesta en valor" (Moreno 1999: 325), "etnoscopia” (Turgeon 2003: 155), "producción" (Kirshenblatt-Gimblett 2001: 44) o "intervención social" (Hernández Ramírez y Ruiz Ballesteros 2008: 134), coinciden con la que aquí proponemos en dos aspectos ${ }^{4}$. En primer lugar, todas definen el patrimonio cultural o, mejor dicho, la patrimonialización, como un proceso, cuyo origen y desarrollo depende de los intereses y valoraciones de los agentes implicados. En segundo lugar, sostienen que la especificidad de los bienes culturales está en su capacidad para simbolizar la identidad colectiva.

Sus diferencias se sitúan en la mayor o menor importancia otorgada a otras variables sociales, culturales o económicas que, obviamente, también concurren en la patrimonialización. Por ejemplo, en la actualidad hay dos a tener muy en cuenta. Por un lado, los intereses vinculados al prestigio que da a los promotores el poner en marcha o consolidar un proyecto patrimonial o museístico. Por otro, los intereses económicos, relacionados con el turismo y el desarrollo local, que en muchos casos parecen prevalecer sobre los identitarios. Aun así, como sostiene Prats, "estamos hablando de activaciones patrimoniales, promovidas por el turismo, pero de activaciones patrimoniales al fin, y, por tanto, se quiera o no - sea de nosotros o de los otros- de representaciones de la identidad" (1997: 46). Establecido el campo patrimonial y legitimados los bienes culturales, otros intereses pueden explicar el devenir del campo, siempre y cuando no se cuestione la doxa. Cuestionada o refutada ésta, aquél desaparece.

Hoy en día, muchos proyectos patrimoniales y museísticos no suelen presentar conflicto alguno en la selección y legitimación de una u otra identidad, ni en los bienes culturales elegidos para simbolizarla. No obstante, que los proyectos no sean conflictivos, tampoco significa que haya un consenso acerca de la propuesta identitaria que presentan, ya que muchos de los procesos de patrimonialización pasan habitualmente desapercibidos para el colectivo social o son ignorados por la gran mayoría. En estos casos, cuando el capital social (Sennett 2006: 58) con respecto a un bien cultural es bajo o inexistente, o la vinculación social hacia él es exigua o nula, la ausencia de conflicto o el aparente acuerdo social no se produce por aquiescencia sino por indiferencia; una cuestión que debería conducir a los promotores patrimoniales a reflexionar acerca de la pertinencia del objeto seleccionado para ser considerado como un bien cultural.

4 Obviamente hay otros autores que las definen o las utilizan de manera diferente. 
No ocurre lo mismo en lo relativo a los usos de los bienes culturales. Definida y legitimada la propuesta identitaria, seleccionados los bienes culturales para simbolizarla, los conflictos surgen principalmente en ese nivel. Como afirma García Canclini, "pese a la enorme importancia que aún tienen la preservación y la defensa, el problema más desafiante es ahora el de los usos sociales del patrimonio" (1999: 22).

Partiendo de estos principios teóricos y tras un vaciado de la información documental y bibliográfica, y la realización de una serie de entrevistas, describiremos y analizaremos la constitución y el desarrollo del campo patrimonial en Legazpi, a partir de una antropología social centrada en los "intereses, motivaciones y estrategias" (Méndez 2009: 97) de los agentes implicados.

\section{EL CONTEXTO: LEGAZPI Y LA PRODUCCIÓN DEL HIERRO}

El municipio de Legazpi se ubica en la comarca de Urola-Garaia ${ }^{5}$ del territorio histórico de Gipuzkoa (País Vasco). Su término municipal cuenta con cerca de $42 \mathrm{~km}^{2}$. Es un valle estrecho, de sur a norte, y atravesado por el río Urola que significa agua de ferrerías en vasco. Durante los siglos XIV y XV Legazpi contó con unas 20 ferrerías mayores y menores, que fueron cerrando a lo largo del XVIII y XIX, a medida que se fueron introduciendo nuevas técnicas de producción del hierro, especialmente el alto horno. Cerradas las ferrerías, las actividades económicas principales en el municipio fueron la agricultura y la ganadería; a finales del XIX un 80\% de la población activa se dedicaba al sector primario, viviendo poco más de 1.000 habitantes en las 40 casas que constituían el núcleo urbano y en el centenar de caseríos diseminados por el término municipal.

A lo largo del siglo xx Legazpi experimentó importantes transformaciones económicas, sociales y culturales, al igual que otros muchos municipios vascos. Esas transformaciones hay que vincularlas directamente con uno de sus vecinos: Patricio Echeverría. "Prototipo de empresario vasco" (Aguirre 2005: 312), fundó en 1908, junto con otros tres socios, la empresa Segura, Echeverría y Cía, para la fabricación de herramientas agrícolas y mineras. En 1919, la sociedad se disolvió, continuando él solo en dicha actividad industrial. En 1938 fundó la empresa familiar "Patricio Echeverría, S.A." (PESA). Además de continuar con la fabricación de herramientas, comenzó también a producir acero. En la década de los 30 PESA contaba con una plantilla de más de 500 trabajadores y 30 años después su número se había

\footnotetext{
${ }^{5}$ Junto a Legazpi, los municipios de Zumarraga, Urretxu y Ezkio-Itsaso constituyen la comarca de Urola-Garaia.
} 
multiplicado por seis, alcanzando los 3.000, un $85 \%$ de la población activa de Legazpi.

Esa transformación económica del municipio estuvo acompañada de importantes cambios sociales, culturales y urbanísticos. El municipio creció espectacularmente. Promovidos por la propia PESA se construyeron varios barrios nuevos, próximos a la empresa, para acoger a los obreros y sus familias. La población del municipio pasó de los 1.200 habitantes en 1900 a los 4.000 cuarenta años más tarde, alcanzando el máximo en 1981 con casi 11.000 censados. Este aumento se produjo por la llegada de inmigrantes de Castilla, principalmente, y de León y Extremadura, en menor medida. Además de la construcción de los barrios, Patricio Echeverría edificó una iglesia, un asilo, dos escuelas, un economato y un dispensario. En definitiva, creó una ciudad nueva con una población muy dependiente del devenir de la empresa, tanto es así que la crisis del petróleo de 1973 y las posteriores crisis y reconversiones en la siderurgia afectaron muy negativamente a todo el municipio. Durante las décadas de los 80 y 90, el número de habitantes descendió hasta situarse en torno a los 8.500 y el paro se situó en torno al 34\%: "Justo cuando Legazpi celebraba el 700 aniversario de su fundación, en 1990, la incertidumbre sobre el porvenir económico de cientos de familias estaba en el aire. La primera mitad de esa década estuvo marcada por una crisis que no tenía precedentes desde el despertar industrial del valle. En una década (1982-1992), P.E.S.A. redujo en un 50\% sus efectivos" (Aguirre 2005: 314).

\section{LA CONSTRUCCIÓN DE UNA IDENTIDAD: LEGAZPI, VALLE DEL HIERRO}

Con motivo de la celebración del cuarto centenario del milagro de la Cruz de Mirandaola, acaecido el 3 de mayo de 1580 en la ferrería de Mirandaola de Legazpi, seis vecinos, "aficionados a la historia local", tal como ellos se definen, publicaron el libro Ferrerías en Legazpi en 1980. El milagro consistió en la aparición de un tocho de hierro con forma de cruz de sólo seis o siete kilos, cuando los ferrones esperaban obtener una colada de unos 250 kilos. Aquel hecho inexplicable se atribuyó a la trasgresión del precepto católico que obligaba a descansar los días festivos, cosa que no hicieron los ferrones. Así se inició un velado culto que la Iglesia autorizó en 1633 (Arbide y Urcelay 1991: 43-51).

Calificado como un "hito" o como la "primera" investigación en su género por algunos de los informantes, el libro Ferrerías en Legazpi "trata del proceso del trabajo de las ferrerías y de la importancia que estos centros de producción y convivencia han tenido a lo largo de la historia en la localidad de Legazpia" (VV.AA. 1980: 6). 
Este trabajo - escriben los autores- no es sino el intento de acercarnos a la historia de un pueblo que dio forma y porvenir a una realidad que con el tiempo contribuyó al desarrollo de la región, forjado sobre todo en el trabajo y el ingenio y cuyo ejemplo palpable tendremos ocasión de ver en la pequeña odisea que supone la lucha por la vida, en el afán de construcción de una comunidad como la de Legazpi (VV.AA. 1980: 14).

La relevancia de celebrar el milagro, que, a su vez, dio pie al trabajo de investigación y a su publicación en su cuarto centenario, no estaría, sostienen los autores, en la aceptación o no de su verdad, sino en el hecho de que la "comunidad de Legazpi, se identificara religiosamente con un acontecimiento relacionado con la base de su vida popular: la elaboración del hierro" (VV.AA. 1980: 13-14).

Más allá de la relevancia científica que tuvo la obra para el conocimiento de las formas de producción del hierro, lo reseñable, en nuestro caso, fue que esos seis vecinos establecieron y legitimaron una vinculación estrecha entre la identidad cultural local y la producción del hierro. Obviamente, como señala uno de ellos, se sabía que la producción del hierro había tenido mucha importancia en la historia del municipio, pero lo que este grupo hizo fue fijar la identidad de los legazpirras con el hierro, propagando y divulgando esa vinculación. La acogida local del libro fue muy buena:

Ese libro fue, un poco, el reconocimiento [...] poner, diríamos, en papel ese valor que tenía el hierro, esa realidad de vestigios, etcétera, que igual todo lo mundo sabía, pero nadie lo había plasmado ${ }^{6}$.

Ese libro significó mucho y sobre todo se vendió enseguida, la gente lo pedía 7 . Fue un descubrimiento para la gente porque no se había hecho nada parecido hasta entonces, tuvo una acogida sensacional, de hecho, se agotó totalmente ${ }^{8}$.

Hay un acuerdo generalizado entre todos los informantes del papel que jugó el libro en la construcción o en la visualización de la identidad local vinculada al hierro. Siguiendo a Anderson fue uno de "los medios técnicos necesarios para la 'representación' de la clase de comunidad imaginada" (1993: 47). Fuera del municipio también tuvo su eco: "Nuestro juicio sobre la monografía es favorable en cuanto al entusiasmo, dedicación y espíritu emprendedor puestos en la empresa [...] el trabajo tiene la frescura y amenidad propias del ánimo que inspiró a sus autores", así calificó el investigador de ferrerías, Díez de Salazar Fernández (1991: 318), el trabajo realizado por esos vecinos.

\footnotetext{
${ }^{6}$ Entrevista realizada el 21 de marzo de 2006.

7 Entrevista realizada el 28 de febrero de 2008.

${ }^{8}$ Entrevista realizada el 11 de mayo de 2009.
} 
Transcurridos 25 años de su publicación, el Ayuntamiento editó el libro Legazpi: Corazón de hierro. En la introducción, el alcalde escribe que este libro "refleja lo que probablemente se ha convertido en una de las señas de identidad más importantes de Legazpi y aceptadas como tal por los legazpiarras: nuestra vinculación con el trabajo en hierro. Algo que, sin duda, marca impronta" (Aguirre 2005: 232) o, como escribió Caro Baroja, "carácter" (1986: 184), refiriéndose a la incidencia del hierro como "símbolo económico, en varios núcleos vascos".

En definitiva, ese colectivo de vecinos fue quien sacralizó el hierro y su producción como bien cultural y quien comenzó a definir el campo del patrimonio cultural en Legazpi. A su vez, ellos se dotaron de los capitales social, cultural y simbólico necesarios para ejercer el control sobre dicho campo?.

Pocos años después de la publicación del libro Ferrerias en Legazpi, el Pleno Municipal del Ayuntamiento acordó crear una escuela-taller para rehabilitar la casa-palacio de Bikuña, un edificio de mediados del siglo XVII y en estado de ruina en aquellos años, con motivo de la celebración del séptimo centenario de la fundación del municipio. Por este motivo el entonces alcalde de Eusko Alkartasuna (EA) ${ }^{10}$ envió una carta a la Dirección de Patrimonio Histórico y Artístico del Gobierno Vasco solicitando la aceptación de la creación de un museo del hierro en la casa-palacio de Bikuña y una ayuda para su realización. Dicha solicitud se justificaba por la larga vinculación del municipio con la producción del hierro, desde su obtención mediante el carbón natural hasta la acería moderna de Patricio Echeverría, lo que había llegado a configurar su idiosincrasia ${ }^{11}$. A la solicitud le acompañaba una memoria en la que se manifestaba:

Es pues indudable la importancia del hierro en la historia socioeconómica y cultural de nuestro pueblo, existiendo una necesidad de crear una institución encargada de la conservación de este patrimonio singular que se está perdiendo. De

9 Un ejemplo: a principios de la década de los noventa llegó al Ayuntamiento de Legazpi una invitación para participar en el Simposi Internacional sobre la Farga Catalana en Ripoll (Catalunya). La entidad local trasladó dicha invitación a dos de los autores del libro, quienes presentaron dos ponencias sobre las ferrerías de agua y los escoriales, corriendo el Ayuntamiento con los gastos del viaje.

${ }^{10}$ De 1987 a 1991 el Pleno Municipal lo constituyeron siete concejales de Eusko Alkartasuna (EA), cuatro de Euskadiko Ezkerra (EE), tres de Herri Batasuna (HB), uno del Euzko Alderdi Jeltzalea/Partido Nacionalista Vasco (EAJ/PNV) y uno del Partido Socialista Obrero Español (PSOE).

${ }^{11}$ Archivo de la Fundación Lenbur (AFL). Caja "Lenbur-inicios-varios proyectos". Carta del Alcalde de Legazpia a la Dirección de Patrimonio Histórico y Artístico del Gobierno Vasco de 17 de enero de 1989. 
ahí la pretensión de que el Museo del Hierro de Legazpi se convierta en el responsable de esta labor. La historia de Legazpi no puede ser pensada excluyendo su actividad ferrona, por ser ésta su alma y su principal modo de vida [...]. La razón de crear un museo del Hierro en Legazpi se debe al interés que tiene el recuperar la imagen de un pueblo con tradición en la industria del hierro. El museo al ser una institución permanente, al servicio de la sociedad y su desarrollo, que adquiere, conserva, investiga y comunica para fines de estudio y educación, testimonios materiales del hombre y su entorno. El museo será un testigo de la historia de nuestro pueblo; concebido como un centro vivo de formación y difusión cultural. Es una labor de una gran proyección social, por cuanto el museo no solo contribuye a la conservación física de ese patrimonio común sino que, desarrolla toda una labor de catalogación, investigación y difusión en un ámbito social ${ }^{12}$.

Por el mismo motivo conmemorativo, el entonces alcalde solicitó a dos de los redactores del libro de las ferrerías, un estudio de la historia de la casa-palacio y de la familia de los Bikuña para que fuera conocido y valorado por el mayor número de posible de personas. Aquel estudio se publicó en 1991 con el título Los Bikuña en la Historia de Legazpi. Ese libro cuenta con tres apartados. El primero dedicado a la familia Bikuña, el segundo, al edificio; y el tercero, a los posibles usos del inmueble una vez rehabilitado.

A este respecto, los dos autores consideraron que el destino adecuado del edificio sería la instalación de un museo, el Museo del Hierro, siguiendo la propuesta de la arquitecta que había redactado el proyecto de rehabilitación. En él se recogería y se mostraría todo aquello que estuviera relacionado con la producción del hierro porque es "poco corriente que la historia toda de un pueblo haya girado desde los orígenes más remotos hasta la actualidad, prácticamente sin solución de continuidad, en torno a la elaboración del hierro, merece ser plasmado en algo tangible" (Arbide y Urcelay 1991: 93). El museo, sostienen los autores, sería un buen complemento a las visitas que ya entonces se podían realizar a la ferrería de Mirandaola, que eran conducidas por uno de los dos autores del libro.

La ferrería de Mirandaola fue rehabilitada o, mejor dicho, recreada, ya que es una actuación casi ex novo en el solar en el que se encontraba dicha ferrería, por el matrimonio Patricio Echeverría y Teresa Aguirre en 1952, abriéndose al público una vez al año, el domingo siguiente a las fiestas patronales de Santa Cruz, para conmemorar el milagro de Mirandaola. Si bien hemos subrayado la función que desempeñó el libro Ferrerías en Legazpi en la construcción de la identidad local, tenemos que destacar también la relevancia que la recreación de la ferrería de Mirandaola ha tenido en la vincu-

12 AFL. Caja "Lenbur-inicios-varios proyectos". Memoria descriptiva adjunta a la Carta del Alcalde de Legazpia a la Dirección de Patrimonio Histórico y Artístico del Gobierno Vasco de 17 de enero de 1989. 
lación del municipio de Legazpi con el hierro. Fue la primera iniciativa de recuperación del patrimonio minero-metalúrgico en España y de las primeras en Europa ${ }^{13}$, si bien aquella recuperación estuvo originada por motivos religiosos principalmente, por una hierofanía siderúrgica en el interior del catolicismo, tal como lo defiende Antonio M. Artola: "En la mente de D. Patricio todo fue adquiriendo forma. La restauración había que hacerla completa: molino, ferrería, horno, fragua, en un palabra: todo un museo en miniatura, de una ferrería del siglo XVI. En este plan ambicioso, la cruz milagrosa ocupaba un lugar privilegiado" (1982: 185). No obstante, esa activación religiosa y patrimonial no tuvo mayor repercusión social en un principio:

Yo he ido desde el comienzo, pero íbamos muy poquitos, muy poquitos. El Ayuntamiento, que entonces era el que era, y muy poquita gente. De hecho, yo creo que en el caserón de al lado de Mirandaola nos albergábamos todos para tomar el hamaiketako, y no había más, muy poca gente [...], unas 30 personas [...] fue adquiriendo dimensión a medida que se le fue dando carácter festivo ${ }^{14}$.

Este cambio comenzó a fraguarse en la década de los 90. En 1990, el alcalde, quien había encargado la redacción del libro de Los Bikuña, y la directora del centro de estudios e investigaciones histórico-arqueológicas "Arkeolan" firmaron un contrato para la realización de un proyecto para el Museo del Hierro en la casa-palacio de Bikuña, así como para el desarrollo de diversas actividades paralelas al Museo. Un año antes de la firma de ese contrato, "Arkeolan" había realizado un proyecto básico del Museo del Hierro y un inventario del patrimonio arqueo-metalúrgico del término municipal. El contacto entre la alcaldía y el centro de estudios se dio porque el alcalde había sido diputado foral de la Diputación Foral de Gipuzkoa y estando en ese cargo conoció los trabajos que "Arkeolan" venía realizando en la rehabilitación de la ferrería de Agorregi en el municipio de Aia (Gipuzkoa), propiedad de la entidad foral.

El encargo municipal del proyecto museológico vino dado por el mismo motivo que en el caso del libro Los Bikuña, y porque "la población [de Legazpi], surgida en torno a primitivas instalaciones productoras de hierro, ha desarrollado una peculiar historia en torno a esas actividad"15. En el proyecto se propusieron cuatro actuaciones: el establecimiento de unos itinerarios por el término municipal para visitar diferentes testimonios de la producción del hierro, la rehabilitación de las ruinas de la ferrería de Olazar,

\footnotetext{
${ }^{13}$ Puche Riart y Mazadiego Martinez (1997). Consulta: 14 de noviembre de 2009.

${ }^{14}$ Entrevista realizada el 11 de mayo de 2009.

${ }^{15}$ Archivo de Arkeolan. Proyecto básico para el Museo del Hierro (Legazpi). Sig. Leg-pr157.
} 
la definición del Museo de Hierro en la casa-palacio de Bikuña y, por último, la realización de un vídeo sobre la historia del hierro en Legazpi. En esta propuesta la reconstruida ferrería de Mirandaola se incluía dentro de los itinerarios, dándose mayor relevancia a la recuperación de la de Olazar.

Así, otro agente, con un importante capital simbólico, especialmente relacionado con la alcaldía, y un altísimo capital cultural en torno al patrimonio arqueológico en el País Vasco, gracias a los muchos trabajos que venía realizando en ese campo (Urteaga 2006), se incorporó al campo patrimonial de Legazpi.

\section{DELIMITACIÓN DE CAMPO PATRIMONIAL: EL HIERRO COMO BIEN CULTURAL ILUSTRADO}

En 1991 se volvieron a celebrar elecciones municipales. En esta ocasión el alcalde elegido fue de $\mathrm{EAJ} / \mathrm{PNV}^{16}$. En esta nueva legislatura el Pleno Municipal acordó ${ }^{17}$ destinar la casa-palacio de Bikuña a Museo del Hierro, tomándose como base el informe redactado por los dos autores del libro de Los Bikuña. Uno de los concejales de EA, el anterior alcalde, propuso que ese informe se complementara con el de "Arkeolan". Sin embargo, con el cambio de legislatura, el proyecto de "Arkeolan", contratado por la anterior alcaldía, comenzó a perder peso. El capital simbólico de ese agente, ante la nueva alcaldía, disminuyó considerablemente. El nuevo regidor municipal apostó por el proyecto de los dos autores del libro de Los Bikuña. El capital simbólico de éstos volvió a crecer después de haber disminuido considerablemente en la anterior legislatura: una relación débil con aquel alcalde de EA y la legitimación que éste dio a "Arkeolan" hizo que su capital decreciera en el campo patrimonial, un campo que ellos habían iniciado e impulsado.

Tras aquel acuerdo municipal, la concejala de cultura de EAJ/PNV informó a la comisión municipal de gobierno ${ }^{18}$ de la próxima constitución de la Asociación de Amigos del Museo y de la puesta en marcha del Museo del Hierro. En efecto, en octubre de 1992, se celebró una reunión para tal fin, en la que estuvieron presentes once personas, todas ellas de Legazpi. Los asistentes fueron: la concejala de cultura de EAJ/PNV, la técnica municipal de cultura, cuatro de los autores del libro Ferrerias en Legazpi, dos

\footnotetext{
${ }^{16}$ El nuevo ayuntamiento se constituyó en el Pleno Municipal del 15 de junio de 1991: cinco concejales del EAJ/PNV, tres de EA, tres de HB, tres de EE y dos de PSOE.

${ }^{17}$ Archivo Municipal de Legazpi (AML). Udal Gorporazioko Bilkura. Aktak. 1991-0615 al 1992-12-22. Sesión del 8 de abril de 1992, p. 14.

${ }^{18}$ AML. Udal Gobernu Batzordea. Aktak. 1992-03-04 al 1994-12-21. Sesión del 14 de octubre de 1992, p. 4.
} 
de los cuales elaboraron el proyecto para el Museo del Hierro, el ingeniero técnico de los servicios municipales y cuatro vecinos. Estos cinco últimos se venían destacando en el municipio por tomar parte en diferentes iniciativas culturales.

A petición de la concejala de cultura, uno de los redactores del proyecto del Museo del Hierro expuso los pasos dados hasta entonces. Así, informó a los presentes de que el Ayuntamiento les había encargado un proyecto, declarando que tuvo conocimiento del de "Arkeolan" el día que el Pleno $\mathrm{Mu}-$ nicipal aprobó destinar la casa-palacio de Bikuña a museo. Aunque en aquel pleno se acordó también la elaboración de un tercer proyecto, integrando los dos anteriores, éste no se llegó a realizar. Además del desencuentro que se dio entre los redactores de cada uno de los proyectos por cuestiones museográficas, "Arkeolan" y el Ayuntamiento rompieron su relación a principios de 1993 como consecuencia del impago de una factura por unos trabajos extras que la entidad local consideraba que no tenía que pagar, pero que "Arkeolan" sostenía que sí estaban justificados. Así, la nueva alcaldía decidió contar definitivamente con los redactores del libro Ferrerías en Legazpi y abandonar el proyecto contratado en la anterior legislatura y promovido por un alcalde de otra formación política. Nos encontramos con el primer conflicto dentro del campo patrimonial de Legazpi, no por cuestiones identitarias, ni, tal vez, tampoco por los usos generales del patrimonio cultural, sino por el control de los mismos. Es decir, un conflicto acerca de quiénes son los agentes legitimados para determinar los usos generales del patrimonio cultural, la creación del Museo del Hierro y los objetivos de esa infraestructura cultural. En este primer conflicto la legitimación, política fundamentalmente, se decantó a favor de los especialistas locales.

Tras la exposición de los pasos dados hasta entonces, surgió el segundo conflicto a lo largo de la reunión, cuando el ingeniero técnico municipal señaló que el proyecto debería ir más allá de la casa-palacio de Bikuña, presentando una alternativa a la opción que venían trabajando los redactores del proyecto del Museo del Hierro. Así, dos propuestas se pusieron sobre la mesa. La primera se articulaba en torno al Museo del Hierro, en la casa-palacio de Bikuña, como va dicho. La segunda consistía en un museo territorio, que englobaba a todo el término municipal de Legazpi, articulándose en tres ejes. El primero, el Parque de Mirandaola, en el cual se incluían la ferrería, un frontón, un recinto para celebrar deportes vascos, una bolera, así como el acondicionamiento de varios paseos para conectar el Parque con el barrio rural de Telleriarte. El segundo eje lo constituían, por un lado, el Refugio y el Centro de Educación e Investigación DidácticoAmbiental, ubicados en las antiguas escuelas de los barrios rurales de Brinkola y Telleriarte, y, por otro, el pantano de Barrendiola. El tercero 
consistía en la recuperación de viejos caminos y de vestigios ligados al hierro, diseminados por todo el territorio municipal, proponiendo una red de paseos "de forma que resultaría un espacio atractivo a todas luces". Por estos motivos el ingeniero técnico sostuvo que el Museo del Hierro se debería ubicar en el Parque de Mirandaola y no en la casa-palacio como se venía barajando.

Además de las novedades puntuales que presentaba esta nueva propuesta con respecto a los dos proyectos anteriores, lo primordial fue que el planteamiento del ingeniero técnico municipal ponía en cuestión o reformulaba la idea general que venían barajando el Ayuntamiento y varios de los allí presentes ya que "el proyecto era inmenso y agotaba todos los temas habidos y por haber, y ahí quedaba el hierro, pues, en uno de ésos, y nosotros le dijimos desde el primer momento [...] que nosotros en ese proyecto no tenemos nada que decir, nosotros estamos en el hierro, en la parte que corresponde al hierro"19, "no lo aceptábamos nosotros, no estaba en nuestras posibilidades, nosotros estimábamos que lo nuestro era mucho más limitado, y limitado al hierro. Entre otras cosas porque nuestra formación profesional estaba muy vinculada al hierro"20 (ya que trabajaban en Patricio Echeverría). Otro informante ${ }^{21}$ presente en la reunión recuerda que la nueva propuesta dejó a los defensores de la primera fuera de juego porque no esperaban que se planteara algo así y porque, además, esa segunda propuesta se hizo de una manera, más o menos, articulada, representándola sobre un mapa del municipio. Es decir, se encontraron ante una nueva proposición que no surgió espontáneamente en el curso de la reunión, sino que se había trabajado previamente a su celebración. Pero hubo algo más, algo que hizo más distantes las dos propuestas: el peso que se dio al turismo en la segunda, a saber, la consideración del patrimonio cultural como un recurso. Es verdad que en las dos propuestas del Museo del Hierro realizadas por "Arkeolan" y por los redactores del libro Ferrerias en Legazpi se tuvo en cuenta también este uso del patrimonio cultural, pero lo fundamental en aquellas era la investigación y el conocimiento de la elaboración del hierro. Por el contrario, en la alternativa presentada se incidía más en los usos económicos, a través del fomento del turismo, de los bienes culturales.

Nos encontramos, pues, ante dos proyectos que representan dos modelos para definir el patrimonio cultural y para actuar sobre él. El modelo ilustrado (Ballart 2002: 117; Fernández de Paz 2006: 3), en torno al cual algunos de los presentes en la reunión habían constituido el campo patrimonial en Legazpi, frente a otro en el que la dimensión económica de los bienes

\footnotetext{
19 Entrevista realizada el 20 de enero de 2008.

${ }^{20}$ Entrevista realizada el 11 de mayo de 2009.

${ }^{21}$ Entrevista realizada el 26 de junio de 2009.
} 
culturales es primordial. Además, como nos lo han señalado varios informantes, nos hallamos ante dos generaciones de legazpiarras. Por un lado, la mayor, que buscaba monopolizar el campo patrimonial, apoyándose en sus capitales simbólico y cultural adquiridos hasta la fecha. Por otro, la más joven, que, con menor capital, buscaba la "subversión", introduciendo nuevos elementos que permitiesen ampliar su capital, variando, en este caso, los criterios de legitimación dentro del campo patrimonial establecido (Bourdieu 2000: 114) al enfatizar los usos económicos de los bienes culturales.

La propuesta del técnico municipal no fue aceptada por la concejala de cultura ya que "en otros sitios se están haciendo cosas y perderíamos el carro - siendo como es Legazpi un sitio con historia para hacer un museo del hierro-"22. Además lo veía con bastante escepticismo, tal como lo recuerda en la actualidad la entonces concejala de cultura ${ }^{23}$. Los dos redactores del proyecto del Museo del Hierro apoyaron a la concejala porque el tiempo apremiaba y porque ya había un acuerdo municipal en tal sentido. En general, la postura de los presentes fue la de llevar a cabo dicho museo en la casa-palacio, si bien no descartaban que se pudiera ir ampliando el proyecto, incorporando otros elementos patrimoniales diseminados en el territorio. El ingeniero técnico municipal replicó, sosteniendo que era mejor abordar un proyecto más global. Además, insistió en que la mejor ubicación del museo sería el Parque de Mirandaola y no el edificio de los Bikuña. La reunión concluyó con el acuerdo de avanzar, por un lado, en la idea de ubicar el museo en la casa-palacio y, por otro, en la creación de la Asociación de Amigos del Museo del Hierro. En definitiva, aquella segunda propuesta fue desestimada, quedando su impulsor al margen de los pasos que se irán dando en los dos años siguientes:

Yo no tenía ningún interés en esto. A mí me han convocado a una reunión, voy, expongo, no sale [...] A mí no me convencía convertir, en un espacio que tienes tanto vestigios..., que el discurso fuese exclusivamente, probablemente lo diría con otras palabras, fuese en un edificio, desde el punto de vista de desarrollo económico que en aquel momento, hay que pensar que estamos en una época de crisis, a mí no me decía nada. Ahora lo veo más claro, pero entonces menos claro, seguramente, pero ya lo vería, viene un autobús de escolares, entra aquí la la casa-palacio de Bikuña], se va, ¿qué nos aporta eso? ${ }^{24}$.

En septiembre de 1993, se constituyó la Asociación de Amigos del Museo del Hierro, Burdiñola ${ }^{25}$. Los fines, según sus estatutos, serán los de po-

\footnotetext{
${ }^{22}$ AFL. Caja "Lenbur-inicios-varios proyectos". Núm. 40.

${ }^{23}$ Entrevista realizada el 20 de septiembre de 2007.

${ }^{24}$ Entrevista realizada el 28 de febrero de 2007.

${ }^{25}$ Término vasco que en castellano quiere decir "ferrería".
} 
tenciar los aspectos culturales de Legazpi que estén vinculados con el pasado y el presente de la actividad industrial del hierro. Definen a la cultura "como representación de las particularidades de cada colectividad, [que] permite a los ciudadanos definir más claramente su propia realidad y defenderla" ${ }^{26}$. El museo se considera como la principal "expresión artificial" de una personalidad que se reivindica. Los objetivos concretos definidos fueron la localización, recuperación, potenciación o divulgación de cualquier elemento - "mueble, inmueble o documental"- que estuviera relacionado con Legazpi, en particular, y con Gipuzkoa, en general. La primera Junta Administrativa la constituyeron aquellas personas que defendieron la primera propuesta o se decantaron al final por ella en aquella reunión de octubre, es decir, la de la realización del Museo del Hierro en la casa-palacio. Un mes más tarde de su constitución, se hizo la presentación pública a la que asistieron unas 40 personas ${ }^{27}$. Además de explicar sus orígenes y objetivos, se hizo un llamamiento a los vecinos para que se implicasen en la iniciativa, insistiendo en que para ello no era necesario ser un especialista en arqueología o historia, sino, simplemente, tener ganas de colaborar. Asimismo, sostuvieron que sus actividades irían más allá del Museo, como, por ejemplo, la búsqueda de vestigios de la actividad siderúrgica en el territorio, recuperar caminos o recoger testimonios de personas vinculadas al hierro, ya que se quería que fuera un "museo territorio" 28 . En la crónica local del Diario Vasco $^{29}$, el articulista — secretario de la Asociación de Amigos del Museo y autor del libro Ferrerias en Legazpi- escribió que la respuesta de la gente al proyecto fue entusiasta ${ }^{30}$. Según dicha crónica, lo que se buscaba era que la Asociación fuera "un centro atrayente en el tema del hierro". La primera actividad se organizó en noviembre de aquel año y fue una excursión para conocer "los lugares más atrayentes del patrimonio disponible". En la marcha participaron unas veinte personas, siendo "una de las notas distintivas del grupo [...] la presencia de un núcleo de jóvenes, pero cabe destacar la heterogeneidad de profesiones de los participantes, puesto

\footnotetext{
${ }^{26}$ Estatutos de la Asociación de Amigos Museo del Hierro Burdiñola, artículo 25.

${ }^{27}$ Ene Bada!, "Burdin museoko lagunen elkartea aurkeztu zen", 10 de octubre de 1993. Semanario local.

${ }^{28}$ El Correo, "La ruta del metal", 15 de noviembre de 1993.

${ }^{29}$ Siempre que nos refiramos a la crónica o al cronista local lo haremos en referencia al del Diario Vasco. Este periódico, el de mayor difusión en Gipuzkoa, publicaba, y así continúa, prácticamente a diario una crónica acerca del Legazpi, al igual que lo hace del resto de municipios guipuzcoanos.

30 Diario Vasco, "En marcha la asociación de amigos del Museo del Hierro", 21 de octubre de 1993.
} 
que entre ellos había, un doctor en antropología, varios ingenieros, licenciados en historia, periodismo, química, filología vasca, teología etc."31. Estas excursiones se seguirán realizando periódicamente con el objetivo de ir conociendo y divulgando la historia y el patrimonio locales. Transcurridos los años, un informante afirma que aquellas salidas tuvieron repercusión "en un sector, pero no adquirió una dimensión general. Fueron un grupo de 40 o 50 personas, pero de ahí no pasábamos nunca" ${ }^{\text {22 }}$. Con todo, gracias a las actividades y a los trabajos que realizaron, su capital simbólico y cultural se fue ampliando y legitimando, teniendo un peso muy importante tanto en el Ayuntamiento, como entre la población local. Además, hay que subrayar que uno de sus miembros fue, hasta el año 2000, el cronista local del periódico que mayor tirada tiene en Gipuzkoa.

Aquella iniciativa de identificación, recuperación y fomento de la vinculación de la producción del hierro con la población local comenzó a superar los campos del conocimiento y de la identidad cultural, considerándose la posibilidad de explotarse económicamente. En noviembre de 1993, en la crónica titulada "La ruta del metal" del diario El Correo se subrayaba que, ante el presente y futuro incierto de Legazpi, urgía la necesidad de poner en marcha nuevas iniciativas y que el Museo del Hierro podría ser una, al estar ubicado en un recorrido turístico, el constituido por el Santuario de Loyola en Azpeitia, el Casco Histórico de Oñate y la Basílica de Aranzazu. En este sentido, el siguiente titular del periódico El Mundo de aquel mes no podía ser más explicito; "Legazpi ya no es de 'acero': la dependencia respecto a un metal en crisis llena la localidad de parados y jóvenes jubilados"33. No era sólo dependiente de la producción de un metal, sino de una sola empresa. Toda la actividad, como ya hemos mencionado, giraba en torno a la empresa que fundó Patricio Echeverría. Con todo, según aquella crónica, en una coyuntura de recesión económica intensa y pesimismo creciente, el turismo todavía no se contemplaba como una alternativa clara: "algunos, como Tere, una joven de 28 años, apuntan que 'el agroturismo, aunque no solventará todos los problemas es un campo a trabajar". Si bien, como manifiesta otro entrevistado en dicha crónica, cuando "un pueblo ofrece su hospitalidad es porque ya no hay nada más".

Antes de concluir el año 1993, aquella dinámica patrimonial dio un giro importante. La concejala de cultura y la técnica de cultura asistieron a las

31 Diario Vasco, "La Asociación de Amigos del Museo del Hierro promueve varios itinerarios", 9 de noviembre de 1993.

32 Entrevista realizada el 11 de mayo de 2009

33 El Mundo, "Legazpi ya no es de 'acero': la dependencia respecto a un metal en crisis llena la localidad de parados y jóvenes jubilados”, 24 de noviembre de 1993. 
jornadas "Museos y patrimonio cultural: modelos de gestión y difusión" 34 , destinadas a agentes y dinamizadores culturales de entidades públicas y privadas. Su objetivo fue el de dar a conocer aspectos relacionados con la interpretación y comunicación del patrimonio cultural. Lo allí escuchado les hizo cambiar de opinión con respecto a la propuesta presentada en aquella reunión por el ingeniero técnico municipal:

Lo que vio en las jornadas eran proyectos turísticos, proyectos turísticos que se valían del patrimonio cultural [...] Y a medida que iba escuchando aquellos proyectos, [la concejala de cultura] se iba dando cuenta que el mapa que vio encima de la mesa en la reunión que convocó en Bikuña podía tener semejanzas con muchas cosas de las que estaba allí escuchando ${ }^{35}$.

A saber, que la idea del ingeniero técnico municipal venía a coincidir con algunas de las propuestas realizadas en las jornadas, en particular, con aquellas que proponían el uso del patrimonio cultural como un recurso para fomentar el turismo y el desarrollo local:

Esto es lo que nos [refiriéndose a la concejala de cultura y otros agentes] está diciendo Aurelio [ingeniero técnico], me imagino que salvando las distancias de los conceptos, pero en el sentido de que..., porque éste [ingeniero técnico] tenía un planteamiento del Maestrazgo, de recursos diferentes, de integrarlos. Esto nos suena a esto, a museo territorio o al concepto de coger todo el pueblo y no al concepto de coger y hacer el museo en un edificio ${ }^{36}$.

Así, a mediados de diciembre el Ayuntamiento entregó a la Directora de turismo del Gobierno Vasco el denominado Plan de desarrollo cultural, de ocio y turismo, que en gran medida recogía la propuesta que un año antes había presentado el ingeniero técnico municipal. La Directora de turismo estimó interesante el plan, animando a la concejala de cultura a continuar por ese camino e invitando al ingeniero técnico municipal a varias reuniones en las que se abordaron cuestiones relacionadas con el turismo y el patrimonio cultural. Tenemos que subrayar que en aquellos años el turismo era una actividad inexistente en Legazpi y en el País Vasco, a excepción de la zona costera, y que algunos colectivos sociales del País Vasco lo consideraban como una amenaza a los valores tradicionales. Una postura

${ }^{34}$ Organizadas por la Diputación Foral de Gipuzkoa y dirigidas por la empresa K6 Gestión Cultural, se abordaron tres grandes temas: la recuperación del patrimonio y su difusión, el patrimonio en su entorno cultural y natural, y el patrimonio y el turismo. Para desarrollar esos temas se invitaron a especialistas de Canadá, Noruega, Francia, Portugal, Cataluña, Teruel y País Vasco, quienes presentaron sus experiencias.

${ }^{35}$ Entrevista realizada el 27 de septiembre de 2007.

${ }^{36}$ Entrevista realizada el 28 de febrero de 2007. 
que se puede rastrear en el País Vasco desde comienzos del siglo Xx (Castells 2000: 360).

NuEVOS USOS EN EL CAMPO PATRIMONIAL: EL HIERRO COMO RECURSO CULTURALECONÓMICO

Ese cambio de orientación acerca de los usos del patrimonio cultural llevado a cabo por el Ayuntamiento de Legazpi se concretó cuando éste entró en contacto con la empresa Internacional Bask Consulting, S.L. (IBK-IBC) a comienzos de 1994.

No obstante, a lo largo del año 1993 el ingeniero técnico municipal siguió trabajando en aquella propuesta de museo territorio, concretándola en enero de 1994 en el informe Proyecto para el desarrollo económico del Parque Natural-Artesanal de la cabecera del Urola: Legazpi $i^{37}$. La propuesta se justificaba por la crisis económica en la que estaba inmersa la empresa $\mathrm{Pa}$ tricio Echeverría que estaba desolando Legazpi. Aquella situación crítica obligaba a buscar alternativas a la producción del acero, proponiéndose la puesta en valor de todo el patrimonio cultural ubicado en el territorio municipal, tal como lo planteó en 1992. El presupuesto para la realización del proyecto fue valorado en 1.102 millones de pesetas (el gasto del Ayuntamiento en aquel año fue de 268 millones), estimándose que se podrían crear 32 puestos de trabajos estables, más otros 58 temporales.

Con todo, quien explicitará, concretará y formalizará la propuesta será IBK-IBC. Para los especialistas de esa empresa el modelo de desarrollo industrial conocido en Legazpi ya nunca iba a volver, por lo que se hacía necesario explorar y abrir nuevos campos de desarrollo económico. De esta manera irrumpe en el campo patrimonial de Legazpi otro agente que reforzó y legitimó una de las dos opciones que se venían barajando, ya que los de Burdiñola continuaban con sus trabajos en torno al hierro, contando también con el apoyo del Ayuntamiento.

IBK-IBC presentó al Ayuntamiento la Propuesta del plan para la revitalización de la economía rural y urbana de Legazpi ${ }^{38}$. El objetivo era proponer soluciones imaginativas, ante la crisis económica del sector siderúrgico, poniendo en valor los recursos disponibles del territorio que estuvieran en sintonía con los programas de revitalización económica de la Unión Europea. Para ello, propusieron la elaboración de un plan de viabilidad de lo

${ }^{37}$ AFL, caja "Lenbur-inicios-varios proyectos". Proyecto para el desarrollo económico del Parque Natural-Artesanal de la cabecera del Urola: Legazpi.

${ }^{38}$ AFL. Caja "IBK-IBC". Propuesta del plan para la revitalización de la economía rural y urbana de Legazpi. 
que denominaron "fuerzas tractoras". Estas fuerzas eran el entorno natural del municipio, el turismo rural, verde o cultural y, por último, las ferrerías y el trabajo artesanal. La propuesta fue aceptada por la alcaldía, firmándose un contrato para la redacción de un plan. Además de su elaboración, en el contrato se estableció que IBK-IBC tendría que asesorar al Ayuntamiento acerca de la posibilidad de recibir fondos europeos para su ejecución.

Los miembros de Burdiñola denunciaron la firma del contrato por haberse realizado "a dedo" 39 . Probablemente el motivo fue su paulatina exclusión del campo patrimonial a pesar de los trabajos que venían realizando, como eran, entre otros, los trabajos de limpieza de los vestigios de las ferrerías, las excursiones por el término municipal para mostrar y difundir los restos de las ferrerías y otros elementos patrimoniales vinculados al hierro, la publicación de artículos y cuadernos o la impartición de conferencias. Durante esa legislatura el Alcalde de EAJ/PNV intentó mantener una relación fluida con Burdiñola, pero su capital simbólico y cultural ante el poder político local se iba debilitando, a medida que la cuestión de los usos económicos y del turismo se iba incorporando al campo patrimonial y se iban integrando nuevos agentes, como fueron, además de los de IBK-IBC, los técnicos de empleo del Ayuntamiento y de la Sociedad de Desarrollo Industrial SORTU.

También el grupo municipal de EA, quien promovió la construcción del Museo del Hierro en la legislatura anterior, denunció el contrato firmado con la empresa IBK-IBC porque se aprobó en la comisión municipal de gobierno y no en el Pleno Municipal. A ese respecto un representante de ese grupo municipal sostuvo:

Que un asunto de esta envergadura, relacionado con el futuro económico del pueblo, debía de haberse tratado en Pleno, y manifiesta que si este tipo de cosas van a hacerse así, que el equipo de gobierno asuma todas las responsabilidades por hechos como éste, y no lance acusaciones a la oposición de actitudes obstruccionistas o se dedique a ensuciar la actividad de su grupo ${ }^{40}$.

Lo que estaba en juego no eran cuestiones formales, sino quién o qué grupo municipal se haría con las riendas de un proyecto novedoso, aunque presentara muchas dudas. En enero de 1995 a propuesta del alcalde se constituyó una comisión de seguimiento, formada por un miembro de cada grupo político ${ }^{41}$.

39 AFL. Caja "Burdiñola - 1". Acta de la reunión realizada con Burdiñola el 10 de mayo de 1995.

${ }^{40}$ AML. Udal Gorporazioko Bilkura. Aktak. 1994. Sesión del 16 de marzo de 1994, p. 7-8.

${ }^{41}$ AML. Udal Gorporazioko Bilkura. Aktak. 1995. Sesión del 18 de enero de 1995, p. 7-8. 
En mayo de 1994, IBK-IBC entregó el plan Legazpi: una propuesta de revitalización de la Economía ${ }^{42}$. Ante la mala situación socioeconómica del municipio, los redactores del plan sostuvieron que las soluciones vendrían por dos argumentos que posee Legazpi: la tradición industrial y los recursos naturales, cuyos aprovechamientos llegarían bajo la forma de artesanía industrial y turismo verde. El fomento de esta segunda actividad económica estaría apoyado en la generalización de los periodos de ocio, la saturación del turismo de sol y playa y una demanda creciente por conocer historias y culturas locales. No obstante, los redactores subrayaron dos problemas a los que tendría que hacer frente el plan; la movilización de los agentes locales hacia esas nuevas formas económicas y la competencia que comenzaba a emerger en esas nuevas actividades económicas.

"Un plan posibilista tendrá que ver con la manera de lanzar una mirada novedosa a un material antiguo, de utilizar lo conocido para fines completamente distintos de los usuales" ${ }^{\star 3}$. Para ello propusieron ofertar un producto territorial que, partiendo del Parque de Mirandaola, se extendiera a los barrios rurales de Brinkola y Telleriarte. Este producto lo denominaron Parque natural artesanal de Mirandaola. También plantearon la creación de una escuela-taller de forja tradicional —esta idea también era considerada en los proyectos precedentes - ya que permitiría a las nuevas generaciones formarse en trabajos con perspectivas económicas de futuro. La escuela-taller sería a su vez un museo visitable con un potencial turístico y con un producto artesanal de un alto valor añadido. Así mismo expusieron que en el desarrollo del plan se debería contar con la participación de la empresa de Patricio Echeverría, es decir, de la empresa privada en un proyecto municipal relacionado con la cultura, con el patrimonio cultural. Una propuesta novedosa para aquellos años en el País Vasco.

Aprobado el plan por el Ayuntamiento y a propuesta de la alcaldía, el ingeniero técnico municipal fue liberado de parte de los trabajos que realizaba en el departamento municipal de servicios para dedicarse a la implementación de las propuestas realizadas por IBK-IBC. Esta designación fue criticada por los miembros de Burdiñola ya que la alcaldía no contó con nadie $^{44}$, según sostuvieron.

El cronista local, miembro de Burdiñola, mostró un rechazo parcial al

\footnotetext{
${ }^{42}$ AFL. Caja "IBK-IBC". Legazpi: una propuesta de revitalización de la economía.

${ }^{43}$ AFL. Caja "IBK-IBC". Legazpi: una propuesta de revitalización de la economía, vol. 1, p. 15 .

${ }^{44}$ AFL. Caja "Burdiñola - 1". Acta de la reunión realizada con Burdiñola el 10 de mayo de 1995.
} 
plan de IBK-IBC. Por un lado, lo calificó de original e innovador en sus propuestas $^{45}$, pero, por otro, manifestó que:

En su día, y cuando se facilitó la información inicial respecto a la propuesta de encomendar este proyecto a IBK por un importe de seis millones de pesetas, se percibió un optimismo esperanzador en algunas de las manifestaciones recogidas, que denotaban que se podía haber topado con una iniciativa de la que podrían obtenerse sus frutos interesantes. Posteriormente, y una vez encomendada la realización del estudio, el silencio en torno al mismo ha sido absoluto, pactado entre los que han seguido el proceso de su realización, sin que se hayan aportado más datos ${ }^{46}$.

La Asociación de Amigos del Museo, así como los miembros de la corporación municipal fueron informados, según la crónica local, a finales de año, una vez finalizado el estudio ${ }^{47}$.

En el ámbito de la comarca, la iniciativa turística y patrimonial no tenía repercusión alguna. No se consideraba que la puesta en valor del patrimonio cultural y el fomento del turismo pudiera ser una alternativa estratégica al desarrollo industrial. Así, en el Plan Estratégico de la comarca de UrolaGaraia, elaborado a finales de 1994, no se tuvieron en cuenta posibles iniciativas patrimoniales y turísticas a desarrollar. El Plan se ideó como un instrumento social para movilizar e involucrar desde abajo a toda la socie$\mathrm{dad}^{48}$, definiéndose tres unidades estratégicas de actuación para canalizar las expectativas y los recursos de la comarca y, de este modo, diversificar la economía. Las unidades estratégicas fueron la dinamización industrial, la mejora y adecuación de la formación y, por último, la mejora de la calidad de vida, desarrollando las infraestructuras y el urbanismo. Solamente, dentro del objetivo octavo, "Mejora de la calidad de vida", se mencionaba la puesta en valor de unas rutas temáticas, entre las que estaba la Ruta del Hierro en Legazpi, sin hacer mención expresa al turismo. No obstante, el Ayuntamiento de Legazpi ya había comenzado a dar los primeros pasos en el fomento del turismo. A finales de 1994 publicó dos folletos turísticos en los que se proponían varios itinerarios a realizar, a pie o en bicicleta, en el término municipal ${ }^{49}$.

45 Diario Vasco, "IBK entrega al Ayuntamiento su propuesta para lograr la revitalización económica", 6 de julio de 1994.

${ }^{46}$ Diario Vasco, "La conmemoración del solsticio de verano, celebrada con buen ambiente", 25 de junio de 1994.

47 Diario Vasco, "El Ayuntamiento informa del plan de revitalización tras el estudio de IBK", 22 de diciembre de 1994.

${ }^{48}$ Archivo de la Fundación Lenbur, caja "Comarca Urola Garaia - 1". Plan estratégico de Urola Garaia - Informe final, p. 4.

${ }^{49}$ Diario Vasco, "La captación del 'turismo verde' una interesante oferta para el municipio", 11 de agosto de 1994. 
A partir del trabajo realizado por IBK-IBC, el Ayuntamiento elaboró, en octubre de 1994, el Plan de actuaciones para el desarrollo de la iniciativa; naturaleza y artesanía del bierro ${ }^{50}$, en el cual se incluían siete áreas de actuación: el proyecto de Mirandaola, la escuela de forja artesanal, la viabilidad y el mercado de la forja artesanal, la creación de una fundación, los usos del medio ambiente, la creación de escuelas taller y, por último, el fomento del turismo rural. Con el objetivo de implicar a diferentes agentes económicos y sociales en el Plan, el Ayuntamiento y, especialmente, el ingeniero técnico de los servicios municipales llevaron a cabo una ronda de reuniones con dichos agentes. Se reunieron con los responsables del departamento de economía de la Diputación Foral de Gipuzkoa con los que trataron fundamentalmente cuestiones relacionadas con las ayudas europeas. También tuvieron algunos encuentros con representantes de los departamentos de agricultura, medio ambiente y cultura de dicha entidad foral. Con los de cultura hubo un pequeño desencuentro ya que en aquellas fechas la Diputación Foral estaba rehabilitando la ferrería de Agorregi en Aia, lo que era visto como una competencia que podría echar por tierra el proyecto de Legazpi. Así, los representantes municipales consideraron aquella iniciativa patrimonial como algo artificial: la historia legitimaba a Legazpi como el sitio más idóneo, y, por tanto, la ubicación natural de la puesta en valor de una ferrería era dicho municipio. Además sostenían que el proyecto de Legazpi traería beneficios sociales y económicos, mientras que el de Aia, ubicado en el interior de un parque natural, difícilmente los podría generar. También se reunieron con representantes del Gobierno Vasco, la entidad financiera Kutxa, la Asociación de Municipios Vascos, el Instituto Nacional de Empleo o la Sociedad de Estudios Vascos. Asimismo, celebraron encuentros con agentes locales. Entre otros, los baserritarras, Burdiñola, varios artesanos locales, la familia de Patricio Echeverría y las asociaciones Ilinti de comerciantes de la localidad, Udana Taldea y Telleriarte Aurrerantz. Con todo, la movilización, la participación o la adhesión al proyecto por parte de las asociaciones y de la población local se entreveía complicada. La crisis económica se estaba trasladando a otros ámbitos sociales, disminuyendo considerablemente la participación ciudadana, según se describe en dos crónicas locales. Sus titulares son significativos: "El dinamismo de la vida socio-cultural legazpiarra ha decaído sensiblemente" cultura y recreo están en una fase de languidez"52; si bien, se responsabilizaba

${ }^{50}$ AFL, caja "Lenbur-inicios-varios proyectos - 1". Plan de actuaciones para el desarrollo de la iniciativa; naturaleza y artesanía del hierro.

${ }^{51}$ Diario Vasco, "El dinamismo de la vida socio-cultural legazpiarra a decaído sensiblemente", 18 de noviembre de 1994.

52 Diario Vasco, "Las actividades de cultura y recreo están en una fase de languidez", 2 de diciembre de 1994. 
también de esta baja participación al Ayuntamiento por su tutelaje y falta de apoyo a las asociaciones culturales. Además, según varios informantes, la excesiva dependencia de prácticamente todo el pueblo a una empresa, a una familia, tuvo como consecuencia el escaso dinamismo que venía mostrando la población de Legazpi. Si Patricio Echeverría y su familia favorecieron el desarrollo económico del municipio e, incluso, hicieron de él y de una gran mayoría de legazpiarras lo que fueron, a su vez adormecieron su dinamismo, cuando no lo reprimieron. Ante cualquier propuesta alternativa a su control económico, social y cultural, la respuesta era severa.

A principios de 1995 el Ayuntamiento presentó otro plan: Legazpi, naturaleza y artesanía del hierro, siguiendo lo establecido en los anteriores. La presentación de ese plan no trajo la adhesión generalizada de los partidos políticos del municipio. Según el cronista local, la proximidad de las elecciones municipales hizo que los partidos políticos se mostraran prudentes ante el plan presentado. Incluso algunos miembros del grupo municipal del alcalde mostraron también un cierto escepticismo. Quienes sí manifestaron su desacuerdo claro fueron los miembros de Burdiñola. Denunciaron la opacidad de algunas de las fases de la redacción del plan y pusieron en cuestión la viabilidad de su presupuesto: 4.000 millones de pesetas, a 25 años.

En ese periodo de incertidumbres acerca de la viabilidad del proyecto patrimonial y turístico, Burdiñola recibió el espaldarazo de Eduardo Chillida, cuando éste hizo entrega del logotipo que representará en adelante a dicha Asociación, lo que animó a sus miembros a reivindicar a Legazpi como "Valle del hierro" y su materialización en un museo. Otro espaldarazo fue el éxito que alcanzó la distribución de 20.000 copias de un folleto que repartieron en la fiesta del Kilometroak ${ }^{53}$ de octubre de 1994, en Legazpi. El folleto, titulado Legazpi, Valle del hierro, editado en euskara y castellano, trataba de las ferrerías de agua del término, lo que fortaleció y visualizó ante los miles de visitantes a la fiesta la estrecha relación de la identidad local con la producción del hierro. Obviamente, todo esto legitimaba el ser y el quehacer de Burdiñola ante la población y el poder político local. No obstante, a principios de marzo de 1995 se recibió en el municipio una noticia acerca de una resolución europea que determinará definitivamente el devenir de las dos propuestas patrimoniales que estaban en juego.

En aquel periodo preelectoral, principios de 1995, y cuestionándose el plan Legazpi, naturaleza y artesanía del hierro, llegó el primer apoyo real. En el mes de marzo, la Unión Europea, a través de la iniciativa comunitaria RESIDER II, para el periodo de 1994 a 1997, concedió una ayuda de 193

${ }^{53}$ La fiesta anual de las ikastolas de Gipuzkoa suele alcanzar los 100.000 participantes. 
millones de pesetas para la realización del Centro Regional de Interpretación del Hierro o Museo Vivo del Hierro en Legazpi. Ese programa europeo tenía como objetivo acelerar la reconversión económica de las cuencas siderúrgicas más afectadas por los problemas de reestructuración industrial y con especiales dificultades para ajustarse con rapidez a las cambiantes circunstancias económicas. La solicitud a la Unión Europa se realizó vía Diputación Foral de Gipuzkoa, ya que ésta era la entidad encargada de seleccionar las propuestas que se debían presentar ante la institución europea. Además de la de Legazpi, se seleccionaron la recuperación de un espacio industrial en Elgoibar (127 millones), la urbanización del polígono industrial de Eziago en Hernani (118 millones) y la creación de la escuela de formación profesional en la comarca del Urola-Garaia (193 millones), ninguna de ellas vinculada al patrimonio cultural, sino a la actividad industrial. La propuesta fue valorada positivamente porque se trataba "de una actuación incorporada en un proyecto ambicioso denominado Legazpi, naturaleza y artesanía del bierro, que ha asumido el Ayuntamiento y que se ha tratado de buscar financiación a través de diversos programas comunitarios" 54 . La propuesta aprobada, para la primera fase del Centro de Interpretación del Hierro o Museo Vivo del Hierro, proponía recuperar todos aquellos vestigios, canales, presas, ferrerías y antiguos caminos del hierro ubicados en los barrios rurales de Brinkola y Telleriarte, con el fin de mostrar la evolución del trabajo del hierro desde las ferrerías de viento. Siguiendo lo establecido en el plan Legazpi, naturaleza y artesanía del hierro, los objetivos $^{55}$ eran la construcción del Centro de Interpretación, la creación de puestos de trabajo, la potenciación de valores endógenos, la recuperación de técnicas artesanales del hierro y la recuperación del patrimonio industrial. Todo ello, según se sostiene, permitirá potenciar las actividades relacionadas con la producción del hierro junto con las agropecuarias y artesanales, además de otras nuevas como las recreativas, la hostelería, la restauración y el ocio. El elemento de referencia de la propuesta fue la ferrería de Mirandaola.

En la concesión de esa ayuda IBK-IBC desempeño un papel importante. Por un lado, en la estructuración y redacción del documento presentado. Fueron ellos los que lo prepararon, adecuándolo a los criterios de la convocatoria europea. Por otro, en la mediación llevada a cabo ante la Diputación Foral de Gipuzkoa. También hay que destacar el apoyo del entonces diputado foral de economía y turismo del Partido Socialista de Euskadi. Éste decidió apoyar el proyecto:

${ }^{54}$ Informe realizado el 24 de febrero de 1995 por la Diputación Foral de Gipuzkoa para la selección de proyectos RESIDER II.

55 AFL. Caja "Lenbur-actas de reunión". Proyecto del Centro de Interpretación del Hierro. 
Me interesaba mucho el asunto pues, ¿por qué? Porque yo había visto que en Inglaterra, fundamentalmente, pues que se recuperaban cosas industriales, que se ponían al servicio del turismo. Yo que sé, una línea de ferrocarril antiguo. Aquí ahora también se hace, pero en aquel momento, no. Se cerraba la del Urola, en lugar de mantenerla para usos turísticos, mantener los talleres..., mantener la cuestión histórica y que además tuviera, pues, un uso turístico-divulgativo era, era otra época. Lo que era viejo, era viejo y punto. Entonces a mí me interesó mucho el proyecto o la idea ${ }^{56}$.

Y lo defendió a pesar de las reticencias que presentaron muchos de los diputados forales, algunos del mismo partido político del alcalde de Legazpi, que constituían el Consejo de diputados. No compartían la propuesta de apoyar a una zona siderúrgica en crisis con un proyecto turístico y patrimonial. Eran partidarios de iniciativas que impulsaran alguna actividad directamente ligada con la industrial, como fueron las otras tres que se aprobaron.

La concesión de la ayuda tuvo una acogida desigual entre la clase política local. El motivo, las obligaciones a las que tendría que hacer frente el Ayuntamiento para poder recibir la ayuda aprobada, es decir, la inversión o el gasto de otros 193 millones, ya que la ayuda concedida suponía la mitad de la subvención solicitada, que la entidad local estaba obligada a completar. En un periodo de crisis y de disminución de ingresos, algunos políticos y vecinos pensaban que ese gasto conduciría a un mayor endeudamiento y, consecuentemente, a un recorte de las subvenciones, de los gastos o de las inversiones en otros ámbitos. El cronista local mostró claramente su postura en un artículo de opinión:

Resulta un tema crucial, no solamente a la hora de marcar prioridades, porque exige renuncias caso de emprender este camino y también porque "Legazpi, Naturaleza y Artesanía del Hierro" define la trayectoria futura de las inversiones municipales de cara a la pretendida recuperación económica de esta zona ${ }^{57}$.

En esa misma crónica también expresó su sorpresa de que algunos concejales mostraran sus reticencias al proyecto por las obligaciones económicas que traería su puesta en marcha, preguntándose si había un desconocimiento de las mismas entre los miembros de la corporación municipal, cuando se solicitó la ayuda. Acerca de las obligaciones económicas que debería asumir el Ayuntamiento, el propio alcalde mostró su inquietud por

\footnotetext{
${ }^{56}$ Entrevista realizada el 20 de febrero de 2008.

57 Diario Vasco, "Difieren las opiniones de los concejales ante la ayuda del Resider", 28 de marzo de 1995.
} 
el volumen económico de las mismas, según se recoge en el diario El Mundo, al informar acerca de ese ambicioso proyecto ${ }^{58}$ :

¿Qué se va a ofertar al visitante? Se les va a ofertar el Parque y las características o valores patrimoniales y culturales de los pueblos que conforman el parque. Así, Oñati esta planificando vender cultura (universidad) y un patrimonio interesante. Zerain los encantos de un pueblo rural, no salpicado por la degradación industrial. ¿Qué vamos a ofertar nosotros? Nuestra tradición industrial. ¿Cómo? Haciendo que Brinkola y Telleriarte en una $1^{\underline{a}}$ Fase sea ese Museo vivo, el ecomuseo o el centro de interpretación como mejor le queramos llamar. ¿Cómo conseguirlo? Creando una mancha de aceite que se vaya extendiendo. Y ¿̇cuál es esa mancha inicial? Mirandaola 59 .

Tras las elecciones municipales, en junio de 1995, se constituyó el nuevo Ayuntamiento ${ }^{60}$, dándose un cambio en la alcaldía. Para los próximos cuatro años el alcalde elegido fue de EA, hijo del que estuvo a finales de la década de los 80, también del mismo partido. Si en la anterior legislatura el grupo municipal de EA no mostró un apoyo explícito al plan Legazpi, naturaleza y artesanía del hierro, el nuevo alcalde hizo de él un eje estratégico de su acción política. El motivo, según nos lo ha manifestado, fue que se encontró con un proyecto más o menos articulado y original en un contexto de crisis económica, en el que, además, se contemplaba que la participación de asociaciones locales y vecinos fuera uno de sus ejes.

Así, las medidas que tomó, apoyadas por la corporación municipal, fueron la creación de la comisión Legazpi, natura eta burdinaren artisautza ${ }^{61}$, el desalojo de Burdiñola de la casa-palacio de Bikuña para uso exclusivo de la comisión recientemente creada y del ingeniero técnico municipal que venía trabajando en el plan, y la asunción por parte de éste de las visitas guiadas a la ferrería de Mirandaola que ofrecía Burdiñola. Así, el juego patrimonial, iniciado en aquella reunión de 1992, estaba llegando al final de su primera fase. Fue la propuesta del ingeniero técnico municipal, con el apoyo necesario del nuevo alcalde, la que determinará el juego patrimonial a partir de 1995. Posteriormente hubo algunos intentos de involucrar a los de Burdiñola en el proyecto, que no llegaron a fructificar. El motivo

58 El Mundo, "Legazpi recupera el hierro: acogerá un museo 'vivo' que ilustrará la historia de las extintas ferrerías”, 23 de abril de 1995.

59 AFL. Caja "Gobierno vasco. 2. a) Departamento de Industria, Comercio y Turismo". Proyecto enviado al Departamento de Industria, Agricultura y Pesca del Gobierno Vasco el 27 de abril de 1995.

${ }^{60}$ El nuevo Ayuntamiento lo constituyeron cinco concejales de EA, cuatro del EAJ/ $\mathrm{PN}$, dos de $\mathrm{HB}$ y otros dos del PSE.

${ }^{61}$ Legazpi, naturaleza y artesanía del hierro. 
expresado para no incorporarse fue la diferencia jurídica de las dos entidades. Los miembros de la Asociación, integrada por individuos que realizaban sus trabajos de investigación en sus ratos libres, consideraban que difícilmente podían participar en aquél plan municipal que, con el tiempo, contaría con una "estructura de tipo empresarial"62, que exigía una dedicación que ellos no podían ofrecer. Por tanto, estimaron que era más eficaz mantener su autonomía y su ritmo de trabajo.

A finales de 1995 el plan Legazpi, naturaleza y artesanía del hierro/ Legazpi, natura eta burdinaren artisautza pasó a denominarse LENBUR (Legazpi -LE-, natura -N- y burdina -BUR-) ${ }^{63}$, determinándose dos campos de actuación: el Centro de Interpretación del Hierro y el Parque natural-artesanal en torno a la ferrería de Mirandaola. El Parque se inauguró en septiembre de 1996 y el Centro, en 2005, manteniendo sus actividades hasta la actualidad ${ }^{64}$.

\section{CONCLUSIONES}

En una publicación divulgativa editada en 2003 por la fundación LENBUR, se afirma, en el apartado "Razón de ser", que dicha entidad "trata de valorizar el medio natural, las costumbres, el patrimonio cultural y la industria del hierro como símbolo de la identidad cultural de un pueblo y como elemento de proyección hacia el exterior" (LENBUR 2003: 12). Esta afirmación, por un lado, recoge el principio de la doxa del campo patrimonial que hemos definido en la introducción de este artículo y, por otro, presenta los elementos que conducen a la constitución de dicho campo: un colectivo social (la población de Legazpi), un elemento cultural (la producción del hierro) y los procesos de identificación y patrimonialización.

La relación entre esos elementos no viene dada, ni es natural ni es objetiva. Muchos municipios de la cornisa cantábrica y del Pirineo, por poner algún ejemplo, han tenido, como Legazpi, una vinculación histórica con la producción del hierro, condicionando su devenir social, cultural y económico. Sin embargo, esa vinculación no ha dado lugar a proyectos patrimoniales o museísticos encaminados a defender, consolidar o fomentar una identidad cultural ligada a la producción del hierro. Así, si se quiere avanzar en el estudio y en la compresión del porqué y el para qué de los proyec-

${ }^{62}$ AFL. Caja "Burdiñola - 1", escrito del presidente de Burdiñola al Alcalde de Legazpi el 15 de enero de 1997.

${ }^{63}$ Legazpi, naturaleza y hierro.

${ }^{64} \mathrm{~A}$ partir de aquel año nuevos agentes, con sus intereses y valorizaciones, se irán incorporando al juego patrimonial en Legazpi que serán estudiados en otros trabajos. 
tos patrimoniales y museísticos, se tendrán que poner en un segundo plano las características históricas y formales de los bienes culturales y analizar quién o quiénes establecen y consolidan la relación entre un elemento cultural, la identidad y el patrimonio y, por tanto, activan o ponen en valor dichos proyectos. En caso contrario se caerá en una naturalización y objetivación de la relación entre el colectivo social, la identidad y el patrimonio, al igual que ocurrió con el patrimonio histórico-artístico, cosificándose los bienes culturales. Estudiar y analizar el patrimonio cultural como un campo, permite, por un lado, abordar la constitución y el proceso de legitimación de los bienes culturales y, por otro, identificar y analizar los agentes y los intereses que están en juego; lo que "hace bailar a la gente, lo que la hace concurrir, competir, luchar" (Bourdieu 1996: 109) y da lugar a las activaciones patrimoniales e iniciativas museísticas concretas.

No hay a priori unos determinados elementos culturales llamados a ser bienes culturales, si bien, algunos, por su historia o su proximidad a la población local, pueden tener más posibilidades que otros. En Legazpi, unos vecinos, aficionados locales a la historia, algunos de los cuales trabajan en la acería PESA del municipio, establecen la vinculación entre la elaboración del hierro, en lo que se refiere a las ferrerías, y la identidad local. A través de publicaciones, conferencias o actividades culturales, dichos vecinos se dotan de los capitales simbólico, cultural y social suficientes para legitimar su propuesta identitaria, nueva a comienzos de los años 90 del pasado siglo. El poder político local, poseedor del capital económico necesario para hacer viable la propuesta identitaria, la aprueba, al igual que el resto de los agentes que se irán incorporando al campo. Por tanto, no hay conflicto de intereses en el criterio identitario. En Legazpi se da un acuerdo en la concreción de la doxa patrimonial, lo que da lugar a que se inicie y se consolide un proyecto patrimonial y museístico en torno a la producción del hierro.

Sin embargo, donde sí emerge el conflicto es en los usos de los bienes culturales. Aceptada la concreción de la doxa, otros intereses, más allá de los relacionados con la identidad cultural, entran en juego en el campo patrimonial. Así, en primer lugar, nos encontramos con aquéllos relacionados con la obtención del prestigio necesario para controlar sus usos. Como acabamos de mencionar, el grupo de vecinos que constituye el campo patrimonial se dota de los capitales cultural, simbólico y social necesarios para erigirse en el agente legitimado para dirigirlo. En sus inicios, nos encontramos, por tanto, con un control del campo gracias al conocimiento que dichos vecinos tienen de la historia local y de las características formales y funcionales de los elementos relacionados con las ferrerías. En esos primeros años se da una combinación entre el criterio que determina el patrimonio cultural y los que se tenían en cuenta en el caso del patrimonio históri- 
co-artístico; una combinación que todavía se da en muchas activaciones patrimoniales e iniciativas museísticas actuales. Éstas presentan, por un lado, un discurso inicial identitario, pero, por otro, una justificación en base a criterios históricos, en la que los agentes, sus intereses y sus valorizaciones quedan ocultos por la objetividad, la rigurosidad y la cientificidad de la propuesta.

Con todo, en un contexto socioeconómico en crisis y alentados por agentes institucionales, como la Diputación Foral de Gipuzkoa, el Gobierno Vasco y la Unión Europa, quienes fomentan iniciativas culturales en las que los bienes culturales son considerados en gran medida recursos económicos, o como el Ayuntamiento, quien busca iniciativas novedosas anticrisis, otros vecinos, aceptando la propuesta identitaria ya establecida, priorizan los usos económicos del patrimonio cultural sobre los ilustrados, alterando parcialmente los principios de legitimación. Estos nuevos agentes locales, con un discurso más acorde con el de los agentes institucionales, van adquiriendo un mayor capital simbólico, lo que les permite, a su vez, obtener importantes recursos económicos para afianzar sus estrategias y acciones. El capital cultural y el capital social, a nivel supramunicipal especialmente, necesarios en un campo en el que los usos económicos de los bienes culturales como reclamo turístico se van consolidando como uno de los ejes en los que gira el juego patrimonial, son proporcionados a los nuevos agentes locales por las empresas de servicios culturales que se van incorporando al juego. Los capitales cultural y social de aquellos vecinos que establecieron el campo patrimonial no son suficientes para imponerse en un juego en el que la dimensión económica de los bienes culturales, como recurso turístico principalmente, se va priorizando. Así, poco a poco se irán quedando fuera de juego.

Como en Legazpi, en los últimos años se ha extendido y establecido que el patrimonio cultural y los museos pueden ser unos recursos favorecedores del desarrollo socioeconómico de un territorio. El País Vasco cuenta con uno de los modelos que mayor incidencia ha tenido en el afianzamiento de ese principio: el Museo Guggenheim-Bilbao. Aunque hay casos en los que es evidente el impacto económico, convendría no dejarse deslumbrar por los reflejos del titanio. La relación entre la cultura y la economía es mucho más problemática de lo que se defiende y se quiere hacer ver. Presenta muchas contradicciones y conflictos, como sostienen Aas, Ladkin y Fletcher (2005: 29). Convendría que se tuviera en cuenta el siguiente enunciado: "patrimonio + turismo = ¿desarrollo?" (Prats 2003: 127).

Desnaturalizados y subjetivados los criterios históricos y artísticos de las élites, los técnicos y los especialistas, y aceptada la doxa identitaria de los bienes culturales, la categoría de "campo patrimonial" nos permite describir y analizar lo que le es específico, como en cualquier otro espacio cultural: 
el conflicto, la lucha por el control del campo. Todos "sabemos que en todo campo encontraremos una lucha” (Bourdieu, 2000: 112). En caso contrario, nos hallaremos ante un "aparato", en nuestro caso, patrimonial; es decir, un campo sin lucha y sin conflicto, en el que las propuestas identitarias y de usos de los bienes culturales son jerárquicas, verticales y de imposición (Font y Subirats 2001: 196). En definitiva, propuestas que van solamente en una dirección: de arriba abajo.

\section{BIBLIOGRAFÍA CITADA}

Aas, C.; A. Ladkin, y J. Fletcher. 2005. "Stakeholder collaboration and heritage management". Annals of Tourism Research 32-1: 28-48.

Agudo Torrico, J. 1999. "Cultura, patrimonio etnológico e identidad". Boletín del Instituto Andaluz del Patrimonio Histórico 29: 36-45.

Agudo Torrico, J. y Fernández de Paz, E. 1999. "Patrimonio cultural y museología: significados y contenidos", en VIII Congreso de Antropología. Patrimonio cultural y museología: significados y contenidos: 7-15. Santiago de Compostela: Federación de Asociaciones de Antropología del Estado Español y Asociación Galega de Antropoloxía.

Aguirre, J. 2005. Legazpi: Corazón de hierro. Legazpi: Legazpiko Udala.

Aguirre, R. 1995. El turismo en el País Vasco. Donostia-San Sebastián: Txertoa.

Álvarez Sousa, A. 1996. "El constructivismo estructuralista: la teoría de las clases sociales de Pierre Bourdieu". Reis 75: 145-172.

Anderson, B. 1993. Comunidades imaginadas. México: Fondo de Cultura Económica.

Arbide, I. y J. M. Urcelay. 1991. Los Bikuña en la Historia de Legazpi. Donostia-San Sebastián: Gipuzkoako Kutxa Fundazioa.

Ariño Villarroya, A. 2002. "La expansión del patrimonio cultural". Revista de Occidente 250: 129-150.

Artola, A. M. 1982. "La cruz milagrosa de Mirandaola (Legazpia): una hierofanía siderúrgica en el interior del Catolicismo", en Santuarios del País Vasco y religiosidad popular. Segunda semana de estudios de historia eclesiástica del País Vasco: 163-194. Vitoria-Gasteiz: Facultad de Teología de Vitoria.

Ballart, J. 2002. El patrimonio histórico y arqueológico: valor y uso. Barcelona, Ariel.

Bauman, Z. 2001. La posmodernidad y sus descontentos. Madrid: Akal.

Binette, R. 2009. "La contribution des institutions muséales au "capital social" - le cas de l'Écomusée du fier monde (Montréal, Canada)", en Activaciones patrimoniales e iniciativas museísticas: ¿por quién?, y ¿para qué?: 129-150. Bilbao: Servicio Editorial de la Universidad del País Vasco.

Bourdieu, P. 1996. Cosas dichas. Barcelona: Gedisa.

Bourdieu, P. 2000. Cuestiones de sociología. Madrid: Istmo.

Camarena Ocampo, C. y Morales Lersch, T. 2009. "El museo comunitario: un espacio para el ejercicio del poder comunal", en Activaciones patrimoniales e iniciativas museísticas: ¿por quién?, y ¿para qué?: 115-127. Bilbao: Servicio Editorial de la Universidad del País Vasco.

Caro Baroja, J. 1985. El laberinto vasco. Donostia-San Sebastián: Txertoa.

Caro Baroja, J. 1986. Los vascos. Madrid: Istmo. 
Castells, L. 2000. "La Bella Easo: 1864-1936". Historia de Donostia-San Sebastián: 283386. Donostia-San Sebastián: Nerea y Donostiako Udala/Ayuntamiento de San Sebastián.

Cátedra, M. 1998. "La manipulación del patrimonio cultural: la Fábrica de Harinas de Ávila". Política y Sociedad 27: 89-116.

Cuche, D. 2002. La noción de cultura en las ciencias sociales. Buenos Aires: Nueva Visión.

Chevalier, D. 2000. "Avant-propos", en Campagnes de tous nos désirs : patrimoines et nouveaux usages sociaux: IX-XV. París: Maison des sciences de l'Homme.

Díaz Balerdi, I. 2008. La memoria fragmentada: el museo y sus paradojas. Gijón: Trea.

Díez de Salazar Fernández, L. M. 1991. Ferrerías guipuzcoanas: aspectos socio-económicos, laborales y fiscales (siglos XIV-XVI). Donostia-San Sebastián: Kutxa, Gizarte eta Kultur Fundazioa.

Dubuc, É. 2008. "La restitution du patrimoine: un rôle pour le musée? Études de cas dans les communautés innues du Québec et du Labrador (Canada)", en Participación ciudadana, patrimonio cultural y museos: 63-73. Bilbao: Servicio Editorial de la Universidad del País Vasco.

Duclos, J.-C. y J.-Y. Veillard. 1992. "Museos de etnografía y política". Museum 175: 129-132.

Fernández de Paz, E. 2006. "De tesoro ilustrado a recurso turístico: el cambiante significado del patrimonio cultural". Pasos: revista de turismo y patrimonio cultural 4-1: 1-12.

Font, N. y J. Subirats. 2001 "La participación pública en los procesos de agenda 21 local", en Ciudadanos y decisiones políticas: 185-200. Barcelona: Ariel.

García Canclini, N. 1999. "Los usos sociales del patrimonio cultural", en Patrimonio etnológico. Nuevas perspectivas de estudio: 16-33. Granada: Instituto Andaluz del Patrimonio Histórico.

García Canclini, N. 2004. Diferentes, desiguales y desconectados. Barcelona, Gedisa.

García García, J. L. 1998. "De la cultura como patrimonio al patrimonio cultural". Política y Sociedad 27: 9-20.

González-Varas, I. 2003. Conservación de bienes culturales: teoría, historia, principios y normas. Madrid: Cátedra.

Hernández Ramírez, M. y Ruiz Ballesteros, E. 2008. "El patrimonio como proceso social. Intervención, desarrollo y consumo del patrimonio minero andaluz", en Participación ciudadana, patrimonio cultural y museos: entre la teoría y la praxis: 129-148. Bilbao: Servicio Editorial de la Universidad del País Vasco.

Kirshenblatt-Gimblett, B. 2001. "La cultura de les destinacions: teoritzar el patrimoni". Revista d'Etnologia de Catalunya 19: 44-61.

Kymlicka, H. 1996. Ciudadanía multicultural: una teoría liberal de los derechos de las minorías. Barcelona: Paidós.

Lenbur. 2003. Impulsando el Museo-Territorio LENBUR. Legazpi: Lenbur.

Macdonald, S. J. 2003. "Museums, national, postnational and transcultural identities". Museum and society 1-1: 1-16.

Mairesse, F. 2007. "Musée/Thésaurus", en Vers une nouvelle définition du musée?: 167225. París: L'Harmattan.

Méndez, L. 2009. Antropología del campo artístico. Madrid: Síntesis.

Moreno, I. 1999. "El patrimonio cultural como capital simbólico: valoración/usos", en Anuario Etnológico de Andalucía 1995-1997: 325-330. Sevilla: Junta de Andalucía, Consejería de cultura.

Pereiro Pérez, X. y Sierra Rodríguez, X. C. 2005. "Patrimonio cultural: politizaciones y mercantilizaciones", en Patrimonio cultural: politizaciones y mercantilizaciones: 9-23. Sevilla: FAAEE, Fundación el Monte, ASANA. 
Prats, Ll. 1997. Antropología y patrimonio. Barcelona: Ariel.

Prats, Ll. 2003. "Patrimonio + turismo = ¿desarrollo?". Pasos: Resista de Turismo y Patrimonio Cultural 1-2: 127-136.

Prats, Ll. 2005. "Concepto y gestión del patrimonio local". Cuadernos de Antropología Social 21: 17-35.

Prats, Ll. y Santana, A. 2005. "Reflexiones libérrimas sobre patrimonio, turismo y sus confusas relaciones", en El encuentro del turismo con el patrimonio cultural: concepciones teóricas y modelos de aplicación: 9-25. Sevilla: FAAEE, Fundación el Monte, ASANA.

Puche Riart, O. y Mazadiego Martínez, L. F. 1997 "Actuaciones europeas en la conservación del patrimonio minero metalúrgico: una idea a desarrollar", en 49 Congreso Internacional de Americanista, www.naya.org.ar/congresos/indices/indice-ica_arqueolo gia.htm

Rogan, B. 2003. "The Emerging Museums of Europe". Ethnologia Europaea 33-1: 51-59.

Roigé Ventura, X. 2007. "La reinvención del museo etnológico", en Patrimonios culturales y museos: más allá de la Historia y del Arte: 18-42. Bilbao: Universidad del País Vasco.

Sennett, R. 2006. La cultura del nuevo capitalismo. Barcelona: Anagrama.

Turgeon, L. 2003. Patrimoines métissés: contextes coloniaux et postcoloniaux. París y Quebec : Éditions de la Maison des sciences de l'homme y les Presses de l'Université Laval.

Unesco. 2002. Cultura, comercio y globalización. París: UNESCO \& CERLALC.

Urteaga, M. 2006. "Arqueología y museos en Gipuzkoa: las experiencias del Centro de Estudios ARKEOLAN (1986-2005)", en Museos, memoria y turismo: 123-146. Bilbao: Servicio de Publicaciones de la Universidad del País Vasco.

VV. AA. 1980. Ferrerías en Legazpi. Donostia-San Sebastián: Caja de Ahorros Provincial de Guipúzcoa.

Fecha de recepción: 7 de abril de 2010

Fecha de aceptación: 24 de agosto de 2010

RDTP, vol. LXV, n. ${ }^{\circ}$ 2, pp. 303-336, julio-diciembre 2010, ISSN: 0034-7981, eISSN: 1988-8457, doi: 10.3989/rdtp.2010.10 